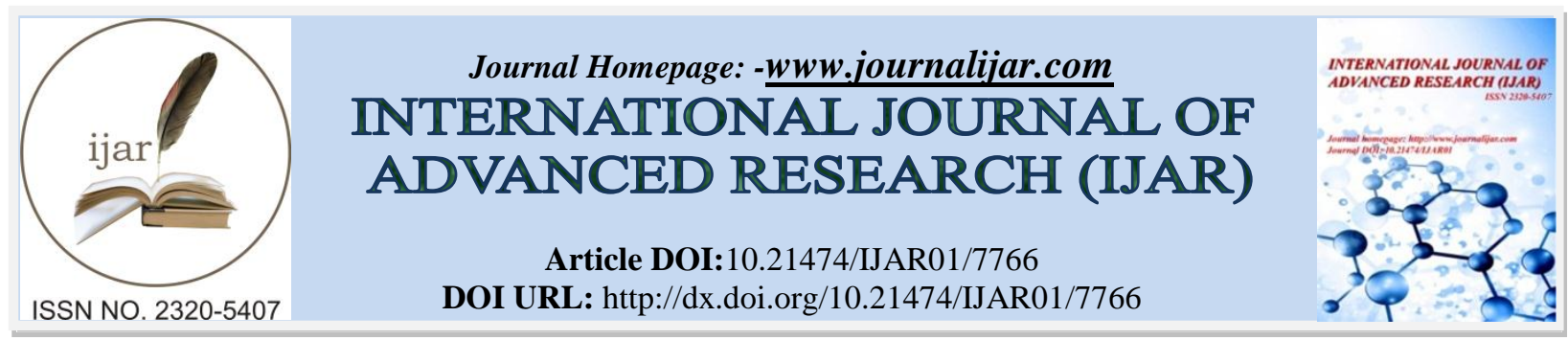

RESEARCH ARTICLE

\title{
ELECTROCHEMICAL DETECTION OF PICRIC ACID USING GLASSY CARBON ELECTRODE MODIFIED REDUCED GRAPHENE OXIDE BY SINGLE-DROP MICROEXTRACTION METHOD.
}

\author{
Victor Emeka Ihuomah ${ }^{1}$, Tony C. Ihuoma ${ }^{2}$ and Sonaimuthu Mohandoss ${ }^{3,4,5^{*}}$ \\ 1. Department of Chemical Sciences, Clifford University, Ihie, Abia State. \\ 2. Cerebral Palsy, North Jersey, USA. \\ 3. School of Chemical Sciences, Alagappa University, Karaikudi, Tamilnadu - 630003, India. \\ 4. Department of Chemistry, National Sun Yat-Sen University, Kaohsiung, 70, Lien-Hai Road, Kaohsiung, \\ 80424, Taiwan. \\ 5. School of Chemical Engineering, Yeungnam University, Gyeongsan, Gyeongbuk 38541, Republic of \\ Korea.
}

\section{Manuscript Info}

Manuscript History

Received: 25 July 2018

Final Accepted: 31 August 2018

Published: September 2018

Keywords:-

Electrochemical sensor, GCE, Picric acid, Reduced graphene oxide, SDME.

\begin{abstract}
The reduced graphene oxide composite-modified glassy carbon electrode (rGO/GCE) was developed as a simple, selective and sensitive electrochemical sensor for determination of picric acid (PA). The rGO was obtained by reduction of graphene oxide obtained via Hummer's method. The synthesised rGO was characterized using Fourier transform infrared spectroscopy (FTIR) and transmission Electron microscopy (TEM). GCE was modified with rGO and the electrochemical properties of the bare and modified electrode were investigated using cyclic voltammetry (CV) and electrochemical impedance spectroscopy (EIS). The results obtained showed that the modified electrode exhibited more excellent electrochemical properties than the bare GCE. The optimum conditions for detection of PA in water using $\mathrm{CV}$ and EIS were as follows: deposition potential at 100 $\mathrm{mV} / \mathrm{s}, \mathrm{pH} 2$, and $0.5 \mathrm{M} \mathrm{H}_{2} \mathrm{SO}_{4}$ was used as supporting electrolyte. The linear regression equation obtained was $\mathrm{I}(\mu \mathrm{A})=0.6432 \mathrm{C}+7.2359$ and the detection limit were calculated to be $0.65 \mu \mathrm{g} \mathrm{L}^{-1}$.
\end{abstract}

Copy Right, IJAR, 2018,. All rights reserved.

\section{Introduction:-}

Nitro aromatic compounds have been used in a number of ways such as in medicine, explosive and pesticides [1]. Some of the unpleasant consequences as pesticides include the presence of residues in the soil, water, air and food. Pesticides have also been shown to disrupt the balance of an ecosystem. In many situations when a pesticide is used, it also kills non-pest organisms. This can drastically alter the natural balance of the ecosystem. They have been proven to be the cause of many health problems such as birth defects, low sperm count, immune system dysfunction neurological damage, cancer (leukemia, non-Hodgkin lymphoma, brain, bone, breast, ovarian, prostate, testicular and liver) etc [2].

The determination of 2,4,6-trinitrophenol (Picric acid;PA) is of great interest because of its high explosive nature, toxicity to human, plants and animals [3]. The determination of low concentration of PA in environmental samples will call for a highly sensitive technique. Many microextraction techniques such as solid-phase micro extraction 
(SPME) for aqueous samples have been used recently [4]. Although these techniques do not need any solvent, they suffer from memory effects. Liquid-phase micro extraction (LPME) technique in which the acceptor phase in the form of a drop of an organic solvent built up at the tip of a syringe and surrounded by an aqueous solution of a sample (donor phase) has been described by Jeannot and Cantwell [5]. This method (in contrast to LLE and SPE), avoids high solvent consumption and does not involve the fiber problem in contrast to SPME. This method is quick and inexpensive.

The present work describes a rather simple method for extraction, preconcentration and determination of PA complemented by electrochemical techniques, the results indicate that LPME possesses a good pre concentration factor, sensitivity, and low detection limit; therefore it could be considered as an efficient technique for analysis of aromatic nitro compounds [6,7]. Selective and sensitive detection of nitro aromatic explosives, in particular PA is of great current interest in both national security and environmental protection because they are not only explosives but also recognized as toxic pollutants.

In this work, the reduced graphene oxide composite-modified glassy carbon electrode (rGO/GCE) was developed as a simple, selective and sensitive electrochemical sensor for determination of picric acid (PA). The rGO were obtained by reduction of graphene oxide obtained via Hummer's method. The electrochemical characterization to prove the rGO modified glassy carbon electrode ( $\mathrm{rGO} / \mathrm{GCE}$ ) for enhancing property. To optimize micro organic drop, extraction time for single drop micro extraction (SDME) method and analyze the extraction of PA by differential pulse Voltammetry (DPV) as rGO modified GCE Vs Ag/Ag Cl. To analyze the low level concentration of PA is determined by this method.

\section{Experimental details:- Apparatus:-}

FT-IR spectra were obtained with JASCO 4600 FT-IR spectroscopy using KBr pelleting, the range of spectra was from 500 to $4000 \mathrm{~cm}^{-1}$. The micrographs of the materials were obtained using transmission electron microscope (JEOL 2100 HRTEM 200V, Tokyo, Japan). Electrochemical experiments were carried out using autolab electrochemical analyzer (GPES Software) it used to apply potential on the working equipped with a three-electrode system using glassy carbon electrode (GCE) (diameter: $1 \mathrm{~mm}$ ) is served as a working electrode. Reference electrode $(\mathrm{Ag} / \mathrm{AgCl})$ was saturated calomel electrode $(\mathrm{SCE})$ and platinum wire as counter electrode. The working electrode was polished to a mirror with $0.05 \mu \mathrm{m}$ alumina slurry, and rinsed with triply distilled water before each experiment. The $\mathrm{pHs}$ were measured on ELICO $\mathrm{pH}$ meter model LI-10T.

\section{Reagents:-}

Natural graphite, $\mathrm{H}_{2} \mathrm{SO}_{4}, \mathrm{NaNO}_{3}, \mathrm{KMnO}_{4}, \mathrm{HCl}, \mathrm{KCl}, \mathrm{H}_{2} \mathrm{O}_{2}, \mathrm{~K}_{2} \mathrm{HPO}_{4}, \mathrm{KH}_{2} \mathrm{PO}_{4},[\mathrm{Fe}(\mathrm{CN}) 6]^{3-/ 4-}$ and picric acid (PA) were bought from Sigma-Aldrich. All chemicals used in the study were of analytical reagent grade and used as received. Electrolyte used in the experiments was $0.1 \mathrm{M}$ acid buffer ( $\mathrm{pH}$ 2). 4-nitrophenol analyte solution was prepared with $0.1 \mathrm{M}$ acidic buffer. All solutions are prepared with deionized water from a Milli-Q system (Millipore).

\section{Synthesis of graphene oxide (GO):-}

Graphene oxide (GO) was synthesized from graphite powder using modified Hummer's method. $1 \mathrm{~g}$ of graphite powder and $0.5 \mathrm{~g}$ of sodium nitrate were mixed together followed by the addition of $23 \mathrm{ml}$ of conc. sulphuric acid under constant stirring. After $1 \mathrm{~h}, 3 \mathrm{~g}$ of $\mathrm{KMnO}_{4}$ was added gradually to the above solution while keeping the temperature less than $20^{\circ} \mathrm{C}$ to prevent overheating and explosion. The mixture was stirred at $35{ }^{\circ} \mathrm{C}$ for $12 \mathrm{~h}$ and the resulting solution was diluted by adding $500 \mathrm{ml}$ of water under vigorous stirring. To ensure the completion of reaction with $\mathrm{KMnO}_{4}$, the suspension was further treated with $30 \% \mathrm{H}_{2} \mathrm{O}_{2}$ solution $(5 \mathrm{ml})$. The resulting mixture was washed with $\mathrm{HCl}$ and $\mathrm{H}_{2} \mathrm{O}$ respectively, followed by filtration and drying, graphene oxide sheets were thus obtained.

\section{Chemical reduction of Graphene oxide (GO):-}

For the reduction of Go, a variety of chemical means may be used to reduce grapheme. The first to be reported was hydrazine monohydrate. For the synthesis of graphene reduction of GO was carried out by adding $20 \mathrm{ml}$ of water to $50 \mathrm{mg}$ of GO powder followed by the addition of $0.5 \mathrm{ml}$ of hydrazine. The mixture was sonicated for one hour and then stirred for 24 hours at $50{ }^{\circ} \mathrm{C}$. After filtration, the black powder of graphene was obtained and dried in vacuum. As prepared graphene material is denoted as $\mathrm{rGO}$ and it is used for sensor fabrication [8]. 


\section{Single Drop Micro extraction procedure:-}

The Single Drop Micro Extraction (SDME) procedure was carried out of using a $50 \mu \mathrm{L}$ micro syringe and taken out the solutions were make sure the lack of air bubbles by washing the syringe several times with organic solvent (dichloromethane). Precision of method was improved by positioning the needle in an aqueous sample as picric acid in acidic buffer ( $\mathrm{pH} 2)$ at a fixed length with stands and clamps. After each extraction, the syringe was washed several times with extractant containing internal standard. A glass vial with $20 \mathrm{ml}$ of volume was used in SDME procedure [9].

The efficiency of SDME was evaluated changing parameters as the extraction times interval $(5,10,15,20 \mathrm{~min})$ and micro drop volume $(5,10,15,20 \mu \mathrm{L})$. The $50 \mu \mathrm{L}$ micro syringe filled with $5 \mu \mathrm{L}$ of extracting solvent was inserted into the vial by piercing the septum. The needle tip was immersed into the solution and fixed $\sim 1 \mathrm{~cm}^{-1}$ below the surface of the liquid. The micro syringe plunger was depressed to expose the solvent drop to allow the transfer of analytes from the aqueous phase to the drop. After micro extraction, the organic drop was retracted back into the syringe and the needles removed off the vial and immediately drop case into the rGO modified glassy carbon electrode for electrochemical analysis. For all the experiments for each concentration solution of $10 \mathrm{ml}$ Picric acid was prepared and used to optimize the optimum experimental conditions then analyzed electrochemical technique.

\section{Electrochemical analysis of picric acid:-}

After micro extraction of organic drop (DCM) was drop case on rGO modified glassy carbon electrode as working electrode, reference electrode $\mathrm{Ag} / \mathrm{AgCl}$ for electrochemical analysis. The cyclic voltammograms were recorded from $-0.5 \mathrm{~V}$ to $2.0 \mathrm{~V}$ at scan rate of $100 \mathrm{mV} / \mathrm{s}$. The differential pulse voltammograms were recorded from $0.5 \mathrm{~V}$ to $2.0 \mathrm{~V}$. The same procedure was carried out for the different concentration of the sample, time variation, and micro drop volume of the sample analysis.

\section{Results and Discussions:-}

\section{Characterization of GO and rGO:-}

Graphene Oxide was synthesized by Hummer's method. The morphological structure of GO was examined by TEM. From the TEM image Fig. 1a it can be seen that the GO, like wrinkled paper, is very thin and homogeneous [10]. These wrinkles may be important for preventing aggregation of GO and maintaining high surface area. Chemically reduced from GO to rGO. Fig. 1b, FT-IR spectrum of GO showed that the peak at $3407 \mathrm{~cm}^{-1}$ attributes to $\mathrm{O}-\mathrm{H}$ stretching vibration, the peak at $1630 \mathrm{~cm}^{-1}$ attributes to $\mathrm{C}=\mathrm{O}$ stretching vibration, the peak at $1402 \mathrm{~cm}^{-1}$ attributes to aromatic ring of $\mathrm{C}=\mathrm{C}$, the peak at $1161 \mathrm{~cm}^{-1}$ attributes to vibration of $\mathrm{C}-\mathrm{O}-\mathrm{C}$ (epoxy), and the peak at $1003 \mathrm{~cm}^{-1}$ attributes to vibration of C-OH (alkoxy). Further the chemically reduced from GO to rGO, the spectra showed that the peak of $\mathrm{C}-\mathrm{O}-\mathrm{C}$ (epoxy group) stretching vibration (at $1161 \mathrm{~cm}^{-1}$ ) disappeared. Two other bands are observed at 607 and $3407 \mathrm{~cm}^{-1}$. The first band can be assigned to peroxide groups and the second to stretching vibration of -OH in hydroxy groups are minimized [11].

Electrochemical behaviors of the modified electrode were investigated using $[\mathrm{Fe}(\mathrm{CN}) 6]^{3-/ 4-}$ as redox process by cyclic voltammetry. As shown in Fig. 2 demonstrates that CVs of bare GCE and rGO/GCE, electrodes were monitored in freshly prepared $1 \mathrm{M}[\mathrm{Fe}(\mathrm{CN}) 6]^{3-/ 4-}(1: 1)$ solution containing $0.1 \mathrm{M} \mathrm{KCl}$ at a scan rate of $100 \mathrm{mV} \mathrm{s}^{-1}$. It can be examined that a well-defined redox couple peaks appeared at bare electrode [12]. After the modification of electrode was coated with rGO, the redox peak currents were much improved due to superior electron conduction ability of rGO as shown in Fig.2. Illustrate the Nyquist diagram of the bare GCE and rGO/GCE. Approximately a straight line was observed in case of $\mathrm{rGO} / \mathrm{GCE}$ which represents a mass diffusion limiting electron transfer process. These results show a higher rate of electron transfer process of $[\mathrm{Fe}(\mathrm{CN}) 6]^{3-/ 4-}$ on the rGO/GCE [12]. 

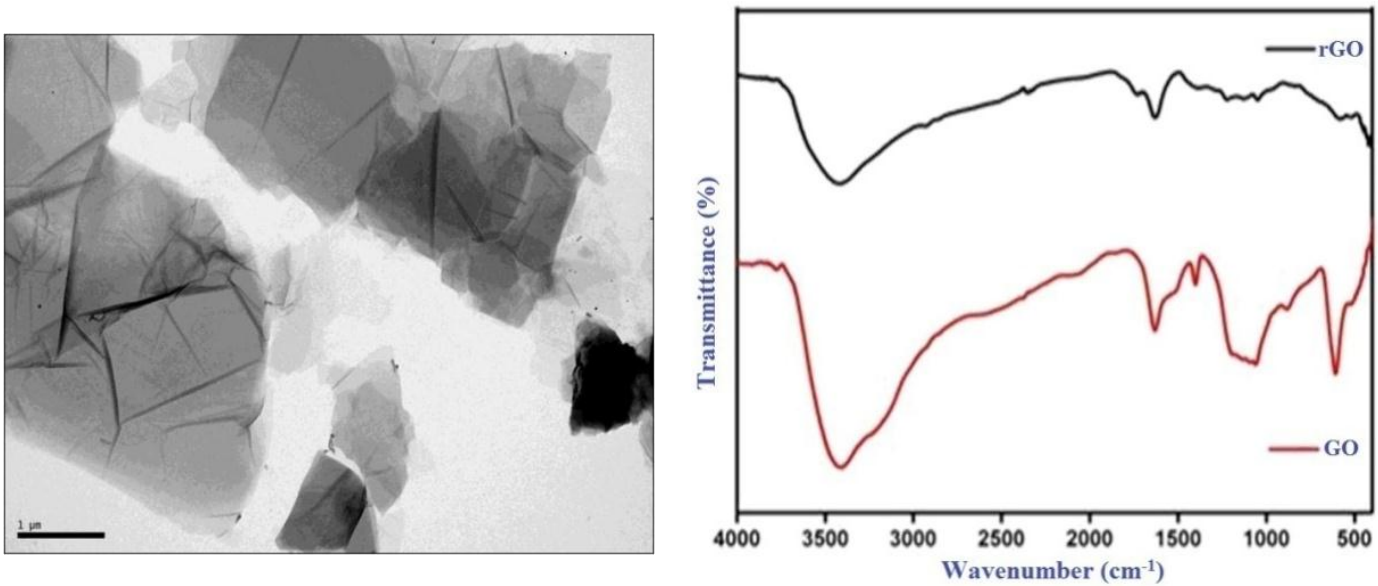

Figure 1:-TEM image of GO and FT-IR Spectra of GO and rGO by Hummers Method
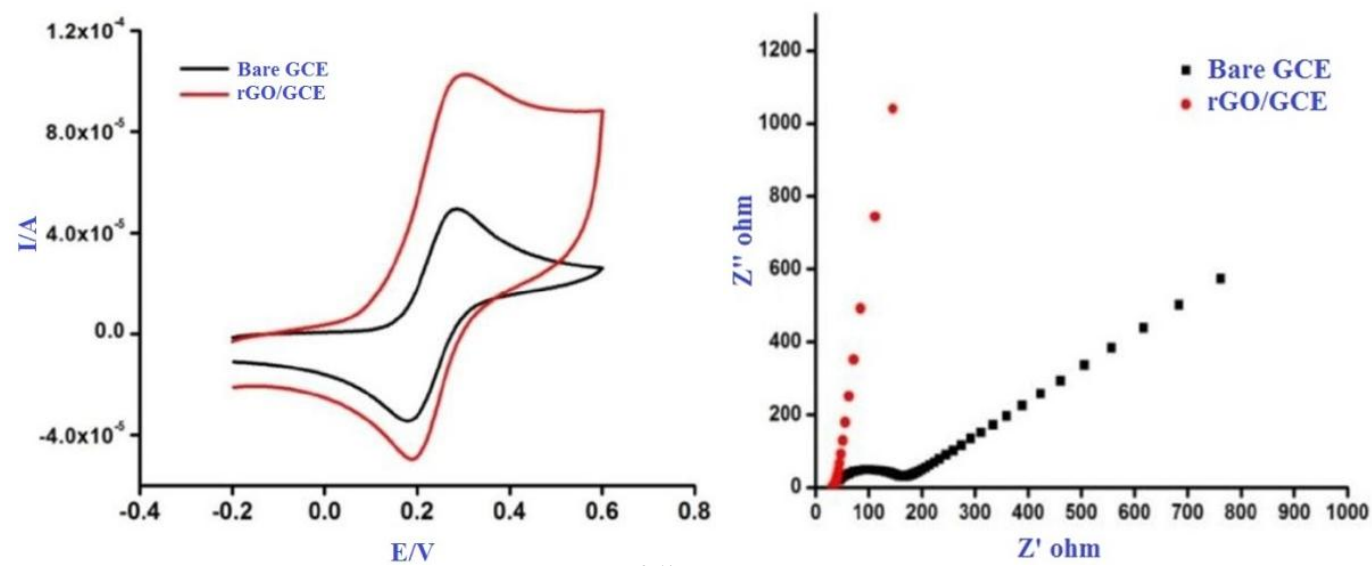

Figure 2:-Cyclic voltammograms of $[\mathrm{Fe}(\mathrm{CN}) 6]^{3-14-}$ as redox peaks on bare GCE and rGO modified GCE Supporting electrolyte KCl solution Scan rate $100 \mathrm{mv} / \mathrm{s}$ and Electrochemical Impedance Spectroscopy.

\section{Electrochemical behaviour of picric acid using rGO:-}

The $\mathrm{pH}$ of the medium has a significant influence on the peak current and peak potential of the electrochemical determination of picric acid. Fig. 3 shows the dependence of the DPV peak current and peak potential of picric acid on the $\mathrm{pH}$, in the range of 2-13. As can be seen, the picric acid signal shifted to more cathodic potentials as the $\mathrm{pH}$ increases. The peak current for picric acid oxidation increased and shifted to more positive potential with increase in $\mathrm{pH}$. The highest current value was obtained at value of $\mathrm{pH} 2$ [13].

A conventional three electrode electrochemical cell used with a platinum wire as an auxiliary electrode, a silversilver chloride $(\mathrm{Ag} / \mathrm{AgCl})$ reference electrode and glassy carbon as a working electrode with diameter of $3 \mathrm{~mm}$ has to employed. The cell made up of glass with a capacity of $25 \mathrm{ml}$ and the cell tops made up of Teflon were used. The cell having three electrodes is working, counter and reference electrodes. Glassy carbon electrode (GCE) with $3 \mathrm{~mm}$ diameter was polished first with 0.3-0.05 $\mu \mathrm{m}$ alumina slurry. After thorough rinsing with double distilled water, the electrodes were sonicated in absolute ethanol and double distilled water for about $1 \mathrm{~min}$, respectively. Before the experiment, the GCE were scanned within the potential range of $-0.2 \mathrm{~V}$ to $1.6 \mathrm{~V}$ in $0.5 \mathrm{M}$ freshly prepared $\mathrm{H}_{2} \mathrm{SO}_{4}$ until stable curves of a cyclic voltammograms obtained. The efficiency of the polished electrode was ascertained using $[\mathrm{Fe}(\mathrm{CN}) 6]^{-3 /-4}$ system. 


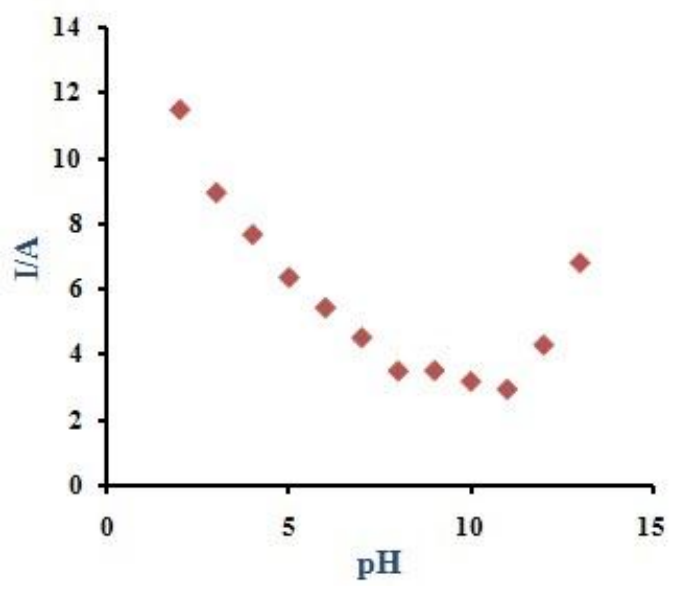

Figure 3:- Effect of $\mathrm{pH}$ vs Current
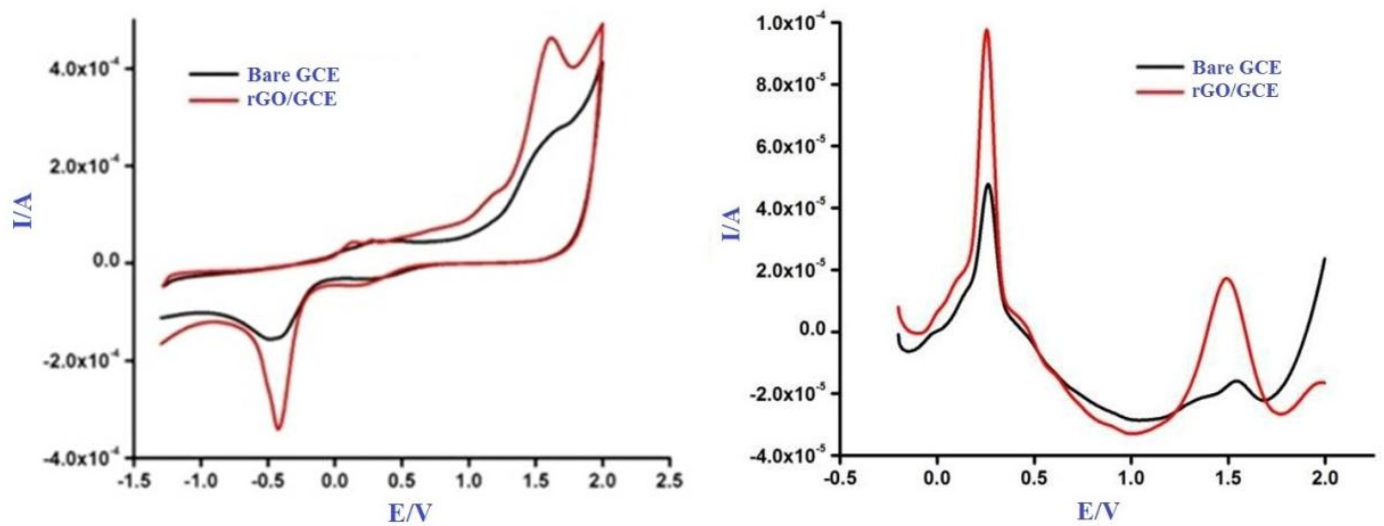

Figure 4:- Cyclic Voltammograms and DPV represents of bare GCE and rGO modified GCE in $1 \mathrm{mM}$ PA solution at scan rate $100 \mathrm{mV} / \mathrm{s}$.

Then GCE was immersed in $0.1 \mathrm{M}$ picric acid. Fig $4 \mathrm{a}$ shows the electro chemical behavior of Picric Acid at bare GCE and modified electrode rGO/GCE analyzed by $\mathrm{CV}$ in $0.1 \mathrm{M} \mathrm{pH} 2$ buffer containing $1 \mathrm{mM}$ Picric Acid at a scan rate of $100 \mathrm{mV} / \mathrm{s}$. It can be observed that a well-defined redox couple peaks appeared at bare electrode. After the electrode modification with $\mathrm{rGO} / \mathrm{GCE}$, there was certainly an improvement in redox peaks current. When the electrode was coated with $\mathrm{rGO}$, the redox peak currents were improved significantly due to superior electro transfer ability of rGO [13]. The electrochemical behavior of picric acid, the figure shows the bare GCE electrochemical irreversible process of one cathodic and anodic peak is visible at peak potential range $-0.4211 \mathrm{~V}$ and $0.2638 \mathrm{~V}$ respectively. Then modified rGO/GCE clearly visible at two redox peak potential at Epa $(0.2541 \& 1.4896 \mathrm{~V})$ and Epc $(-0.4211 \& 0.2307 \mathrm{~V})$ respectively. The cathodic peak potential very sharply. Fig. 4b, represents DPV response were enhanced rGO modified GCE of two anodic peak potential at $0.2491 \& 1.568 \mathrm{~V}$.

\section{Study on SDME technique:-}

The proposed SDME method of extraction and pre-concentration of the studied picric acid explosive, some important experimental parameters, such as volume of extraction and extraction time were investigated and optimized [14]. In standard, the amount of $0.1 \mathrm{M}$ picric acid analytes extracted with the Dichloromethane organic drop is proportional to the drop volume when other parameters such as extraction time, organic solvent and $\mathrm{pH}$ level are unchanged. The outcome of volume of micro drop ranging from $5 \mu \mathrm{l}$ to $20 \mu \mathrm{l}$ was studied. The electrochemical results shown in Fig. 5 indicate that the peak current increase with the increase of the volume of micro drop from $5 \mu \mathrm{l}$ to $20 \mu \mathrm{l}$, when the volume exceeded $20 \mu \mathrm{l}$, the drop became too unstable to swing at the needle tip. From the voltammetric studied the current value is increased from extraction volume $5 \mu 1$ to $20 \mu$ l, below the results, drop volume of $20 \mu 1$ was selected in further studies. 


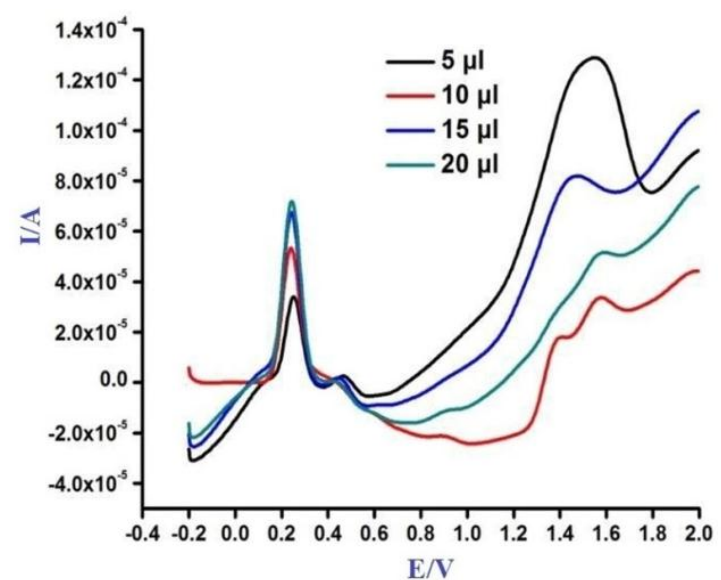

Figure 5:-DPV response of picric acid at different organic drop volume from 5 $\mu 1-20 \mu 1$ on rGO modified GCE scan rate at $100 \mathrm{mV} / \mathrm{s}$. Reference electrode: $\mathrm{Ag} / \mathrm{AgCl}$.

A long extraction time can lead to high extraction efficiency, but always results in great loss of micro drop solvent. Therefore, the selection of extraction time should consider extraction efficiency and micro drop solvent loss. The effect of the extraction time on the extraction efficiency was examined in the range of 5-20 min. The experimental results shown in Tables 1 and Fig. 6, indicate that the extraction recoveries of target analytes increase with the increase of the extraction time, and then decrease slightly. Too long extraction time may result in the depletion of the solvent drop and the poor precision. On the base of these results, the extraction time of 10 min was selected for the following experiments.
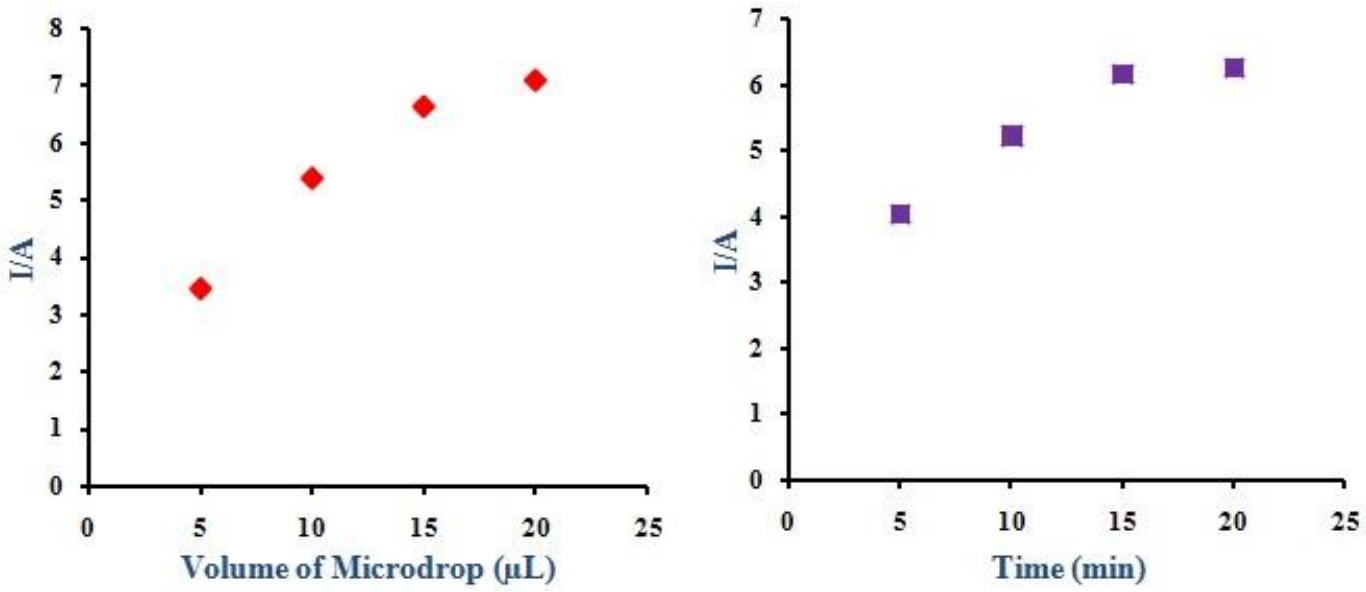

Figure 6:-Effect of extraction volume of Microdrop and Time vs. Current

Table 1:-Effect of extraction volume of Microdrop and Time vs. Current

\begin{tabular}{|c|c|}
\hline $\begin{array}{c}\text { Volume of } \\
\text { Microdrop }(\boldsymbol{\mu L})\end{array}$ & $\begin{array}{c}\text { Current } \\
\mathbf{x ~ 1 0} \mathbf{1 0}^{-5}(\mathbf{A})\end{array}$ \\
\hline 5 & 3.469 \\
\hline 10 & 5.391 \\
\hline 15 & 6.639 \\
\hline 20 & 7.095 \\
\hline
\end{tabular}

\begin{tabular}{|c|c|c|}
\hline Time (min) & $\begin{array}{c}\text { Potential } \\
(\mathbf{V})\end{array}$ & $\begin{array}{c}\text { Current } \\
\mathbf{x ~ 1 0}\end{array}$ \\
\hline 5 & 0.2101 & 4.054 \\
\hline 10 & 0.2101 & 5.229 \\
\hline 15 & 0.2101 & 6.175 \\
\hline 20 & 0.2101 & 6.256 \\
\hline
\end{tabular}

\section{Electrochemical study of picric acid by SDME method:-}

Under the optimal experimental conditions, a series of experiments were performed. The electrochemical behavior is observed by using differential pulse voltammetry method. A series of DPV were recorded after SDME of extraction of micro drop in various concentration of picric acid drop casted on rGO modified Glassy carbon electrode vs. $\mathrm{Ag}^{+} / \mathrm{AgCl}$ in Electrolyte solution of acidic buffer solution ( $\mathrm{pH}$ 2). Table 2 and Fig. 7, shows that DPV 
response was observed for two anodic peaks potential at $0.1857 \mathrm{~V} \& 1.323 \mathrm{~V}$ respectively. From the figure effect several of concentration $\left(1 \times 10^{-3} \mathrm{M}\right.$ to $\left.10^{-7} \mathrm{M}\right)$ of picric acid, the peak current was observed.

Table 2:- Different concentration of picric acid vs. Current

\begin{tabular}{|c|c|c|}
\hline PA Conc. $(\mathbf{M})$ & $\begin{array}{c}\text { Potential } \\
(\mathbf{V})\end{array}$ & $\begin{array}{l}\text { Current } \\
\mathbf{x ~ 1 0}^{-5}(\mathbf{A})\end{array}$ \\
\hline $1 \times 10^{-3}$ & 0.1857 & 5.296 \\
\hline $1 \times 10^{-4}$ & 0.1857 & 3.652 \\
\hline $1 \times 10^{-5}$ & 0.1857 & 2.347 \\
\hline $1 \times 10^{-6}$ & 0.1857 & 0.8949 \\
\hline $1 \times 10^{-7}$ & 0.1857 & 0.7376 \\
\hline
\end{tabular}

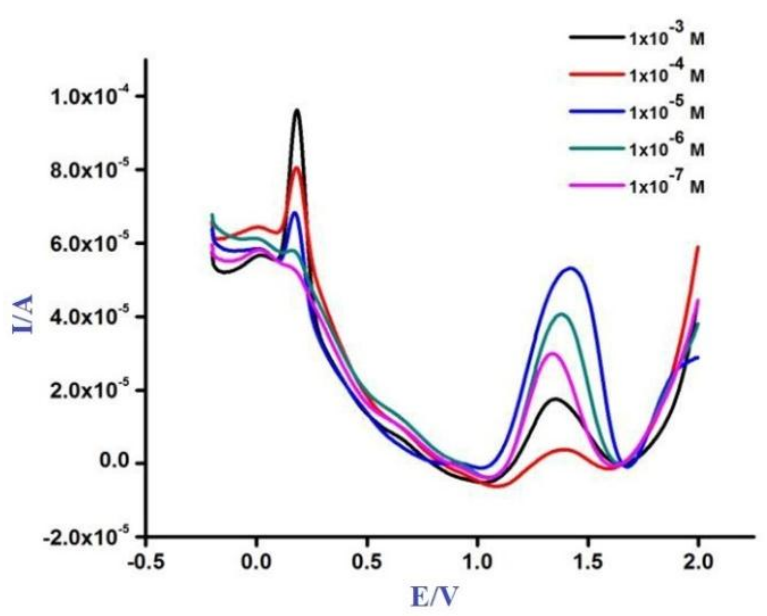

Figure 7:-DPV response of various concentration of PA on rGO modified GCE vs. current responses using pH 2 buffer solution.

\section{Conclusions:-}

In this work, SDME combined with electro chemical technique was developed for the trace-level determination of picric acid in aqueous samples. Some important experimental parameters such as extraction time and micro drop volume were studied and optimized. Under optimal extraction conditions the maximum extraction efficiency for picric acid was achieved. The presence of rGO as modifier on GCE enhanced the detection of PA. The combination of both SDME and rGO modified electrode resulted the low level detection limit, good linearity and repeatability for the detection of picric acid in water. This method is easy-to-handle, cost-effective and more attractive preference to a traditional SDME. 


\section{References:-}

1. K. Ju and R.E. Parales, Microbiology and molecular biology reviews, 74(2), 2010, 250-272.

2. M. Sarwar, International Journal of Chemical and Biomolecular Science, 1(3), 2015, 141-147.

3. M.D. Roldan, E.P. Reinado, F. Castillo and Conrado M. Vivian, FEMS Microbiol Rev, 32, 2008, 474-500.

4. M. Rutkowska, K. Dubalska, P. Konieczka and J.Namieśnik, Molecules, 19, 2014, 7581-7609.

5. M.A. Jeannot and F. F. Cantwell, Analytical Chemistry, 68, 1996, 2236-2240.

6. C.M. Santana, Z.S. Ferrera, M.E.T. Padrón and J.J.S. Rodríguez, Molecules, 14, 2009, 298-320.

7. A.M.A. Alsharif, G.H.Tan, Y.M. Choo and A. Lawal, Journal of Chromatographic Science, 55( 3), 2017, $378-$ 391.

8. A.O. Idris, N. Mabuba, D. Nkosi, N. Maxakato and O.A. Arotiba, International Journal of environmental analytical chemistry, 97(6), 2017, 534-547.

9. B.Hashemi, P. Zohrabi, M. Shamsipur, Talanta, 187, 2018, 337-347.

10. H.M. Nilsson, L.D. Knoop, J. Cumings, E. Olsson, Carbon, 113 2017, 340-345.

11. S. Drewniak, R. Muzyka, A. Stolarczyk, T. Pustelny, M.K. Moranska and M. Setkiewicz, Sensors, 16, 2016, 103-118.

12. S.Li, Q.Zhang, Y. Lu, D. Ji, D. Zhang, J. Wu, X. Chen, Q. Liu, Sensors and Actuators B, 244, 2017, 290-298.

13. M.Mahyari, International journal of environmental analytical chemistry, 96 (15), 2016, 1455-1468.

14. A. Yohannes, T. Tolesa, Y. Merdassa and N. Megersa, Journal of Analytical \& Bioanalytical Techniques, 7 (5), 2016, 1-8. 